\title{
EBSD Microstructure Mapping of Zr47.5Cu45.5Al5Co2 Bulk Metallic Glass Matrix Composite to Ascertain the Effect of Inoculation in Promoting Crystallinity
}

\author{
Muhammad Musaddique Ali Rafique \\ Eastern Engineering Solutions LLC, Detroit MI, USA \\ Department of Metallurgical and Materials Engineering, University of Engineering and \\ Technology Lahore, 5400, Pakistan \\ ali.rafique@hotmail.com
}

Keywords: Inoculation, composite, scattering, diffraction, crystallinity

\begin{abstract}
Bulk metallic glass matrix composites have emerged as competent structural material of future bearing potential structural applications. However, the optimum percentage of crystallinity required to produce enough toughness that it can serve as structural component is still a matter of debate. In this study, an effort is made to address this problem by inoculation. A controlled amount of carefully selected inoculant is introduced in $\mathrm{Zr} 47.5 \mathrm{Cu} 45.5 \mathrm{~A} 15 \mathrm{Co} 2$ bulk metallic glass matrix composite during melting and solidification. Its effect in promoting crystallinity is checked by detailed electron back scatter diffraction (EBSD) mapping. Proper pattern capture, background correction, binning, Hough space transformation, step size selection, indexing and matching with well-defined crystal structure files have shown to reflect upon map quality. This shows and bears direct relation with effect of inoculation. Results from two independent laboratories are reported. Inoculation treatment is shown to be advantageous.
\end{abstract}




\section{Introduction}

Bulk metallic glasses [1-5] and their composites [6-11] have recently re-emerged as new material bearing superior properties of strength [9, 12-16], hardness [17-21] and elastic strain limit [11, 22, 23]. However, they manifest brittleness [19] due to their parent glassy structure, possess inferior ability to absorb energy (poor toughness) [19, 24, 25], and fail catastrophically under the action of applied loads [13, 20, 24, 26]. This behaviour makes them dubious and limits their application. Various applications have been proposed which make use of their superior properties [11, 22, 2735] but still they are limited by their scalability. Efforts have been made to address this problem from various perspective. For example, by external (ex-situ) [36-38] introduction of crystalline particles in melt or internal (in-situ) [39-45] nucleation and growth of same during processing (solidification [22, 33, 46], devitrification [47-50], powder metallurgy [51], foaming [52] or solidstate processing). However, quest for ultimate answer is still far from exhaustion. In-situ introduction of crystalline phases during solidification have proved out to be best solution to tackle this problem [53-55] since its inception by Prof. Johnson's group at Caltech in 2000 [56]. Various groups in the world have produced a multitude of composites using similar philosophy [7, 9-11, $22,23,40,57-68]$. Overtime, various studies have also been reported which shed light on different aspects of their manufacturing [23, 69, 70] and microstructural development [8, 71-73]. These include observations under transmission electron microscopy [74], synchrotron light [75-78] and in-situ studies $[14,74,79,80]$ but none have been made on the detailed use of more recent and advanced electron back scattered diffraction [81-88]. Few efforts have been made in this regard [32, 44, 65, 89-93], but none exist on its application on inoculated composites [22]. This is a new and unique technique which has been reported as complimentary to transmission electron microscopy [86, 94]. It has unique ability to identify [81] and map crystallinity in materials [83, $84,87,95]$. It can not only generate diffraction patterns (kikuchi lines) [96] but can efficiency map [87] the presence of different phases (of distinct crystal structure) [82] in a bulk of material [97] and compare them with existing crystal structures in international crystallographic diffraction database. With the augmentation of energy dispersive X-ray spectroscopy (EDS) detector, it can also generate elemental maps which can serve as input for back scatter diffraction data collection $[94,98]$. It also generates pole figures and grain size histograms which again can be used to determine mechanical properties of material. Application of post processing techniques [99], also help to generate more detailed information about crystal structure of material. In present study, which is part two of two-part study, author aim to bridge this gap. A comprehensive electron back scatter diffraction study is carried out with the help of modern Hiraki electron diffraction detector. Resulting kikuchi patterns are captured on the phosphorus screen. These captured patterns are corrected, converted to Hough space transform and then indexed by comparison with well-known and defined patters in international crystallographic diffraction database. This is postulated and observed to cast effect on resulting phase identification in microstructure of material.

\section{Experimental procedure}

Melting and casting: Melting and casting of small ingots in the form of wedge [22] was performed at CSIRO - Manufacturing, Clayton, Victoria, Australia by employing vacuum arc melting and 
suction casting button furnace. Alloying elements including major $(\mathrm{Zr})$ and minor $(\mathrm{Al}, \mathrm{Cu}, \mathrm{Co})$ were premixed in appropriate amounts with Aluminium foil serving the purpose of wrapper as well as alloying element. A detailed procedure of melting, casting and metallographic sample preparation can be found in a previous study [100]. Electron back scatter diffraction: Electron back scatter diffraction was performed using field emission Teneo microscope at EDAX Laboratories, Draper, Utah. Microscope was equipped with thermally assisted Schottky type field emission gun. Operating voltage was $30 \mathrm{KV}$ while working distance was kept at $25 \mathrm{~mm}$. Microstructure mapping was carried out using Hiraki EBSD detector with maximum speed (count) of 600 indexed points per second. Scan area / area of interest selected was 150 x 130 microns while step size was kept at 0.1 microns. From this, an indexed point per second of around 200 was calculated which was operating parameter in present case. Camera binning of $2 \times 2$ was used. Time taken for one scan was around 3 hours. EBSD detector was operated at lower counts per second to avoid any damage to its phosphorous screen. For proper pattern capture, first, series of EDS mapping for individual elements $\mathrm{Zr}, \mathrm{Cu}, \mathrm{Al}$ and Oxygen was carried out which generated enough data point on which further back scatter diffraction mapping was based. These were converted to Hough transform and indexed with well-known crystal information files present in database of software of machine.

\section{Results and discussion}

Simultaneous energy dispersive spectroscopy (EDS) and electron back scatter diffraction (EBSD) performed on bulk metallic glass matrix composite samples with the help of EDS and EBSD detectors attached with high speed digital cameras enables both to be used as imaging devices. This enables acquisition of images exhibiting topographic, atomic density and orientation contrast. Resulting images and their details are described below

\section{1 $\mathrm{ZrC}=$ zero percent}

Figure 1 (a) shows image quality map of sample with zero percent inoculant. It clearly indicates that there is no crystallinity in material. Background is placid with no precipitation and it indicates formation of $100 \%$ monolithic glassy structure. Similar type of behaviour and effect is observed in scanning electron microscope image of material (Figure 1 (b)). These facts are reinforced by diffraction scattering map shown in Figure 1 (c).

(a)

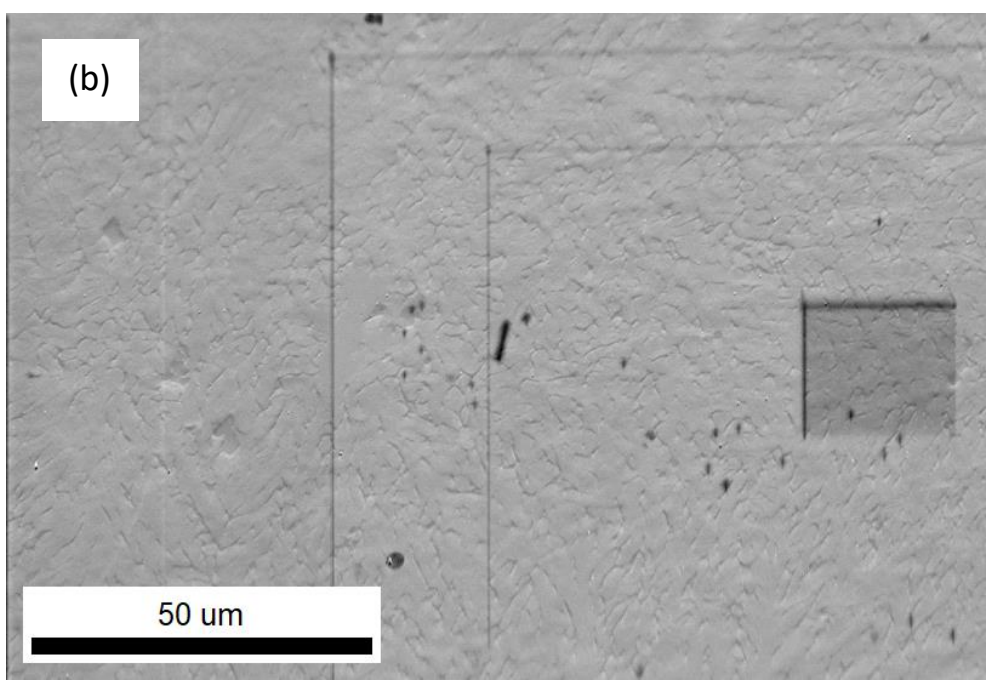




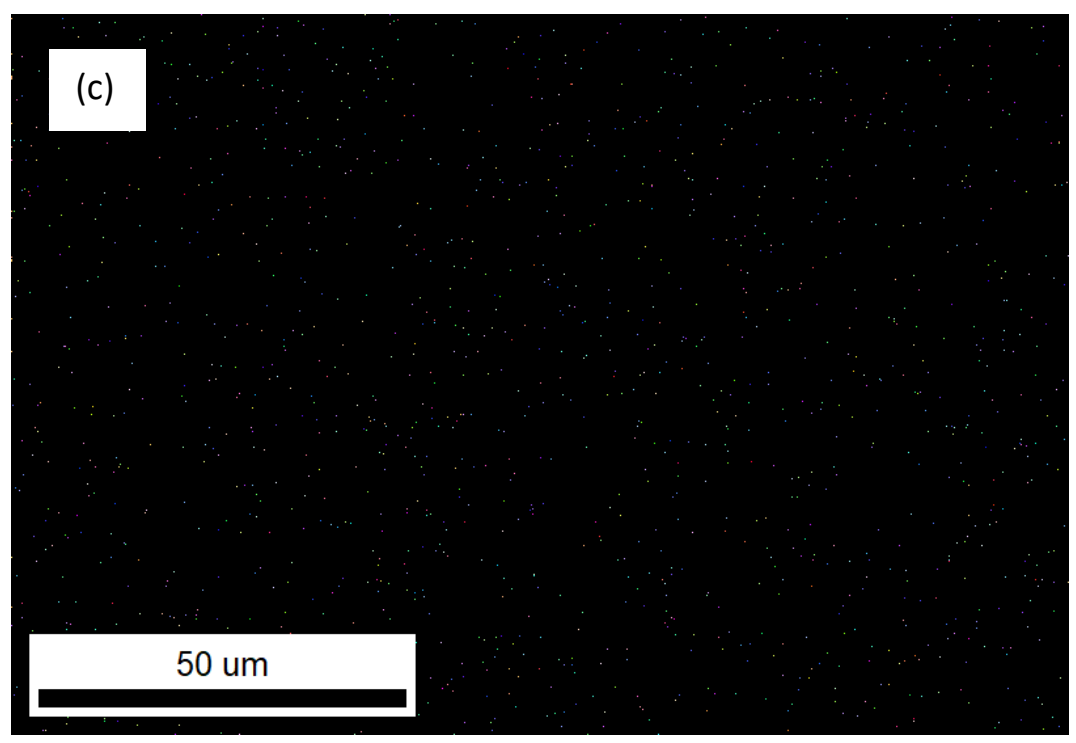

Figure 1: (a) Image quality map of sample with zero percent inoculant, (b) scanning electron microscopy image, (c) phase identification map with crystal orientation

\section{$2.2 \mathrm{ZrC}=0.25 \%$}

Microstructural features developed in bulk metallic glass matrix composite with inoculant percentage $0.25 \%$ are shown in Figure 2 (a) - (p). Simultaneous EDS and EBSD mapping were carried out. First EDS mapping was conducted to generate enough data set which is present in the form of congregation of points on the microstructure. These points serve as input for further crystal structure mapping and determination of orientations in them. This was followed by EBSD mapping at binning of $2 \times 2$ and speed of 200 indexed points per second in an area of $130 \mu \mathrm{m} \times 150 \mu \mathrm{m}$. This methodology generated a very good data set and speed which were adequate for appropriate mapping. Microstructure was depicted in the form of colour coded micrographs. Evidently, it showed eight types of microstructures. These are;

\section{CuZr B2}

Structure: Primitive simple cubic (like CsCl) [39]. Morphology, Spherical to Spheroidal with the inclination to get spheroidal as the time for diffusion is provided. They are soft in nature (Hardness: $3.5 \mathrm{GPa}$ ) while matrix (glass) is hard $(4.9 \mathrm{GPa})$. That is, as the time for diffusion increases alloy tends to form large spheroidal particles. This spheroidal shape is not only the function of diffusion but is also formed as a result of considerable change in kinetics. Higher cooling rates tends to form finely dispersed needle like morphology while at slow cooling rates, sphere tends to form their ideal spherical morphology. These are brittle in nature and are formed because of Aluminium which is $\beta$-destabilizer.

\section{Ductile small body centred cubic (bcc) dendrites}


Structure: These are body cantered cubic in nature. They have yield strength in the range from $900-1000 \mathrm{MPa}$ [101]. Morphology: They were identified to have body cantered cubic $\beta$ dendrite structure primarily as $\beta$-Ti because of Ti in 2003 [101]. Further research in 2008 showed them to exhibit body cantered cubic solid solution dendrites [7]. These are preferably observed along [111] zone axis of one of dendrites which confirms they are body cantered cubic. In conclusion, these are body cantered cubic dendrites. These are neither $\mathrm{Cu} \mathrm{Zr} \mathrm{B} 2$ nor $\beta$ phase.

\section{Face centred cubic (fcc)}

Most likely, they are aluminium crystals as shown by strong signal of Aluminium in EDS maps (Figure 2 and 3 (c)). These may have been brittle $\mathrm{Al}_{2} \mathrm{Zr}$ phase [71] (point 5 below). However, further research is needed to probe this effect and their exact nature.

\section{Small $\mathrm{Zr}_{2} \mathrm{Cu}$ dendrites}

These are cubic $(\mathrm{Fd}-3 \mathrm{~m})$ [58]. These are brittle intermetallic and are formed at the interface of glass and $\mathrm{CuZr}$ B2. These are not observed at $6500-7500 \mathrm{x}$. These are not observed by XRD alone. Only EBSD or TEM can reveal them at 15,000 - 20,000 x. These are primary sites of heterogeneous nucleation of $\mathrm{Cu}_{2} \mathrm{Zr}$ in addition to homogeneous nucleation directly from glass [58].

\section{Brittle $\mathrm{Al}_{2} \mathrm{Zr}$}

These are formed in $\mathrm{CuZrAl}$ ternary alloy in the presence of $\mathrm{Nb}$ [71]. These are evidently observed at $2.0 \% \mathrm{Nb}$ as characterised by XRD. Below $2.0 \%$ their formation is not observed. Further, with the addition of $\mathrm{Nb}$ with the application of tensile force, deformation induced martensitic transformation of $\mathrm{CuZr}$ B2 (primitive simple cubic) to B19' (monoclinic) is observed.

\section{Brittle $\mathrm{Ni}_{2} \mathrm{Zr}$}

This is evidently observed in alloys having Ni only [58]. In present alloy, a phase resembling them is observed. However, as the alloy does not have exact chemistry, this phase can not be ascertained to have exact $\mathrm{Ni}_{2} \mathrm{Zr}$ nature. Further research is needed to determine its exact nature.

\section{7. $\mathrm{Cu}_{2} \mathrm{Zr}$ (hexagonal)}

This is typical phase observed in CuZrAl ternary alloy having nickel. These have symmetry $\mathrm{P}_{3} /$ nmc [58]. This is because of stabilizing effect of Oxygen. They are observed in a recent study by author [100]. However, in alloys having Cobalt, their emergence is not clearly witnessed. Only their resemblance could be ascertained. Further research is needed to verify their presence.

\section{8. $\mathrm{Cu}_{10} \mathrm{Zr}_{7}$ small plates}

Very recently, a report has been published [102] which identify a new phase named as $\mathrm{Cu}_{10} \mathrm{Zr}_{7}$. However, this is reported to be predominantly emerging only in the presence of Be (which is original Viterloy 1). This is intermetallic phase which nucleate and grow at the surface of already precipitated $\beta-\mathrm{Zr}$ dendrite. In present alloy, their presence could be ascertained as $\beta$ stabilizers is present. However, it cannot be justified as chemistry of alloy is not exactly Vit 1. Further, research is required to ascertain and quantify its presence. 


\section{Note:}

1. Bcc dendrites only form when there is Be (e.g. Vit1) [7, 101].. If dendrites are forming in the absence of Be, it means both process and chemistry control are excellent.

2. Why fcc dendrites are appearing? (these could be $\mathrm{Al}_{2} \mathrm{Zr}$ [71] as during EDS mapping $\mathrm{Al}$ is shown to form majority of these long dendrites and Al has fcc structure).

In alloy inoculated with $0.25 \% \mathrm{ZrC}$, microstructures observed are shown in figures below. EDS maps show two types of behaviours. (a) A continuous map consisting of individual elements and (b) spots in continuous map. Spot is characterised as white in $\mathrm{Cu}$ map, dark green in $\mathrm{Zr}$, blue around previous two regions and green in oxygen map. This may be identified as unmelted $\mathrm{ZrC}$ inoculant around which heterogeneous nucleation start. An evidence for this may be inferred from the fact that a lot of footprint of $\mathrm{Al}$ is observed around this point while the centre is rich in $\mathrm{Zr}$. This points towards the fact that $\mathrm{Al}_{2} \mathrm{Zr}$ [71] is formed as $\mathrm{Zr}$ tends to seep away from $\mathrm{ZrC}$ and preferably reacts with aluminium to form primary nucleation site.

$$
\mathrm{ZrC}+2 \mathrm{Al} \longrightarrow \mathrm{Al}_{2} \mathrm{Zr}+\mathrm{C}
$$

Figure 2 (e) shows image quality map of $\mathrm{Zr}_{47.5} \mathrm{Cu}_{45.5} \mathrm{Al}_{5} \mathrm{Co}_{2}$ while Figure 2 (f) shows colour coded orientation map of $\mathrm{Zr}_{47.5} \mathrm{Cu}_{45.5} \mathrm{Al}_{5} \mathrm{Co}_{2}$ with $0.25 \% \mathrm{ZrC}$. These maps clearly show difference from previous maps when percentage of inoculant is zero percent. Marked crystallinity is observed. Primarily two types of phases are identified in these orientation maps. (a) face centred cubic phase and (b) body centred cubic phase. As described earlier, fcc phase may be identified as long dendrites of $\mathrm{Al}$ or $\mathrm{Al}_{2} \mathrm{Zr}$ [71] with branches of small dendrites protruding as off shots from main dendrite. Difference of colour in these dendrites (Figure $2(\mathrm{~g})$ ) points towards orientation change. That is, there are certain regions in the micrograph which are oriented at different angles to each other. These angles may be read in detail from associated pole figures. Grain size histograms show average size to be around $1.2742 \mu \mathrm{m}$. Similarly, a careful analysis of colour coded orientation map of body centred cubic phase show mostly small grains spread all throughout the matrix as threedimensional network. Their size is around $4-6 \mu \mathrm{m}$. They are shown to possess a certain definite orientation relationship between different grains of same phase. Grain size histogram show their size to be $0.6853 \mu \mathrm{m}$. 

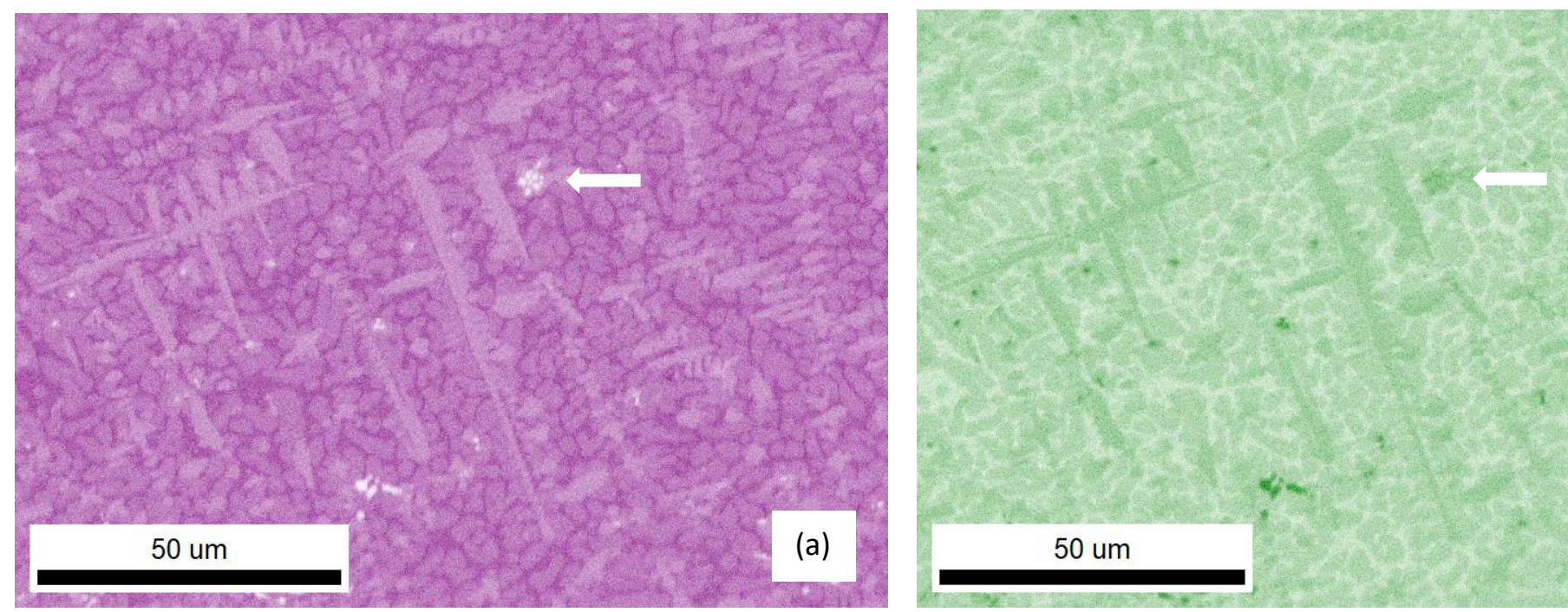

(b)
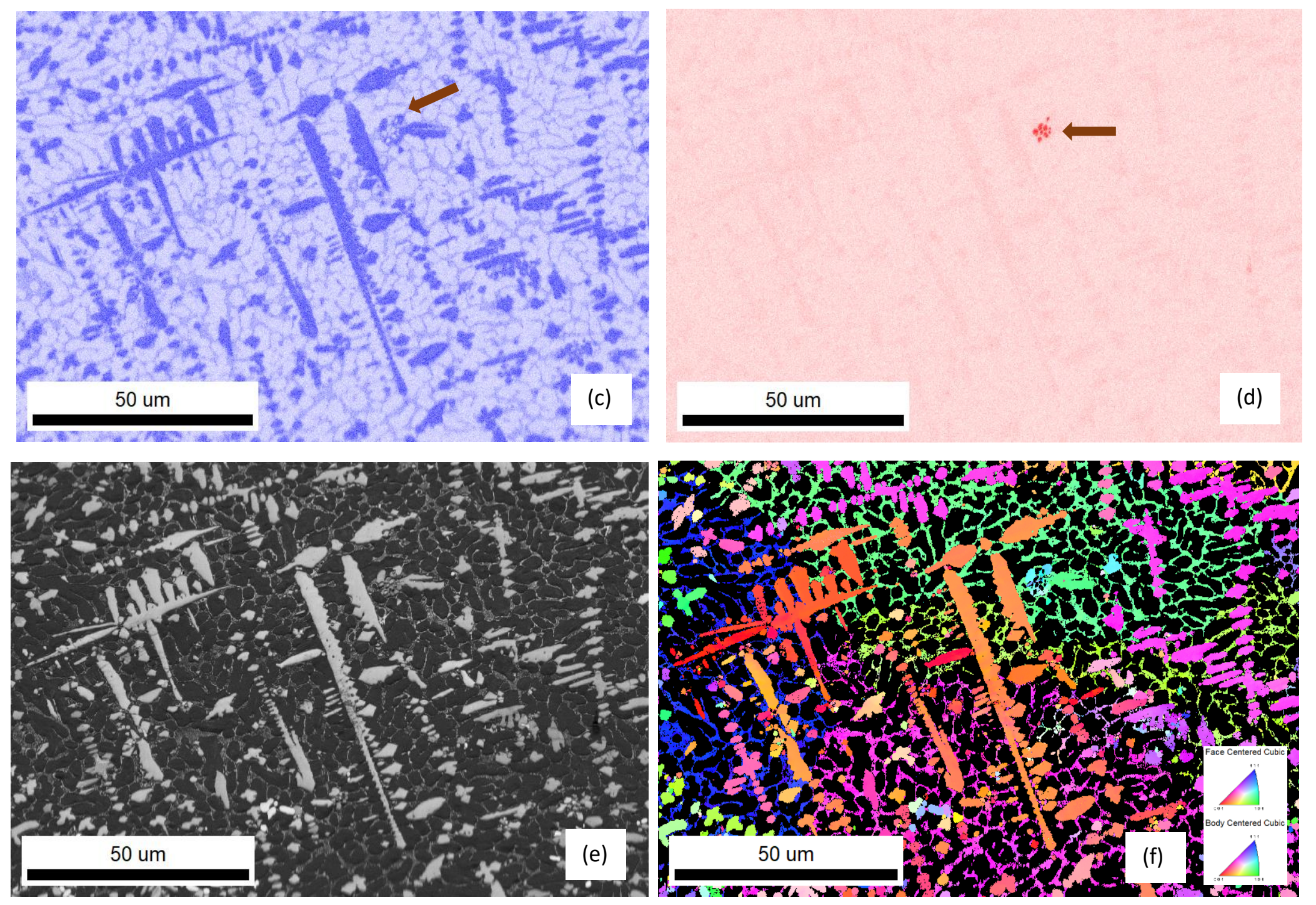


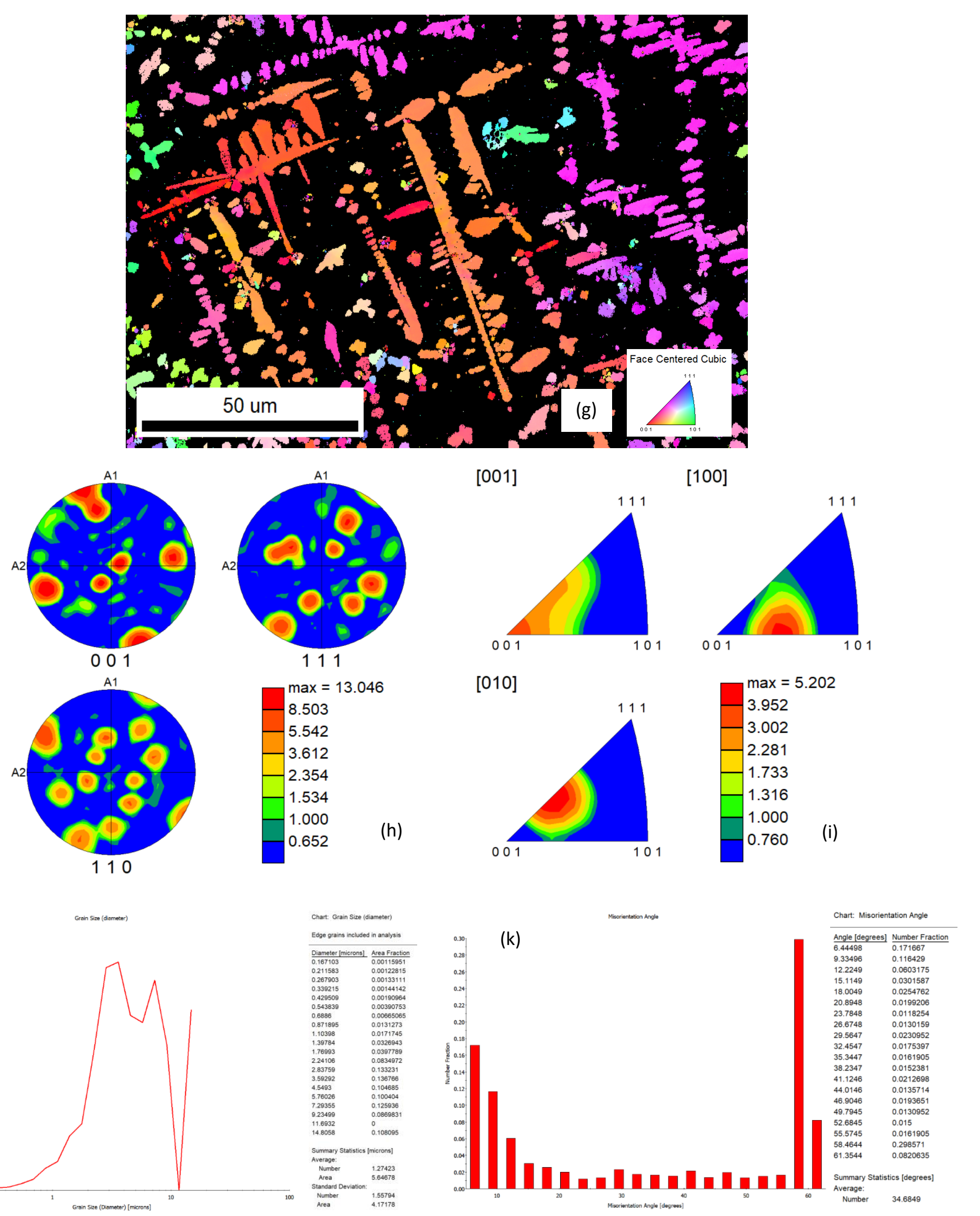




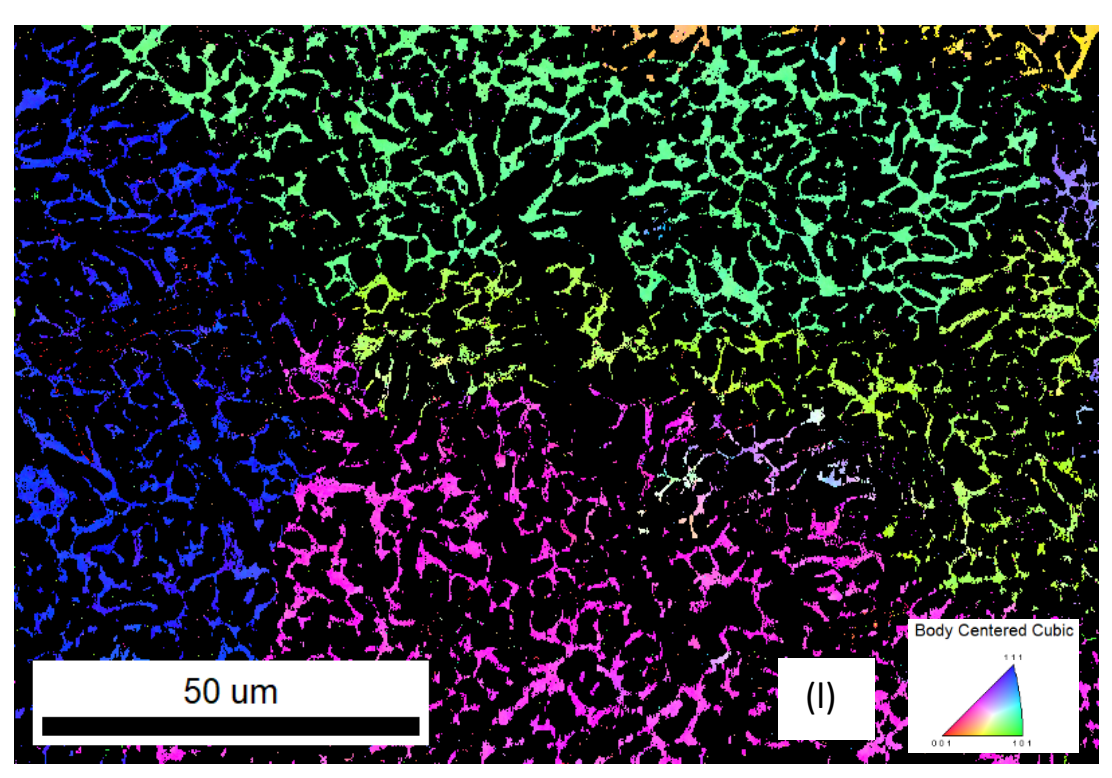

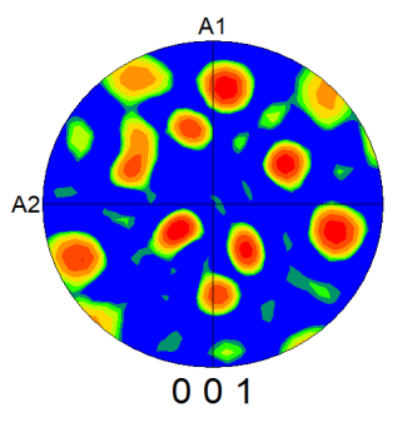
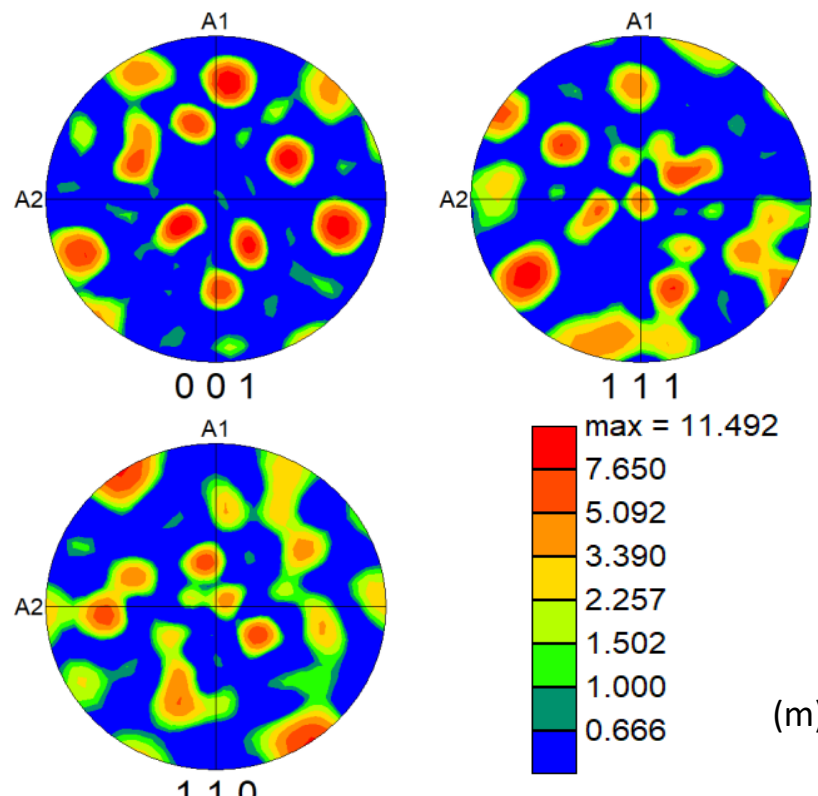

111

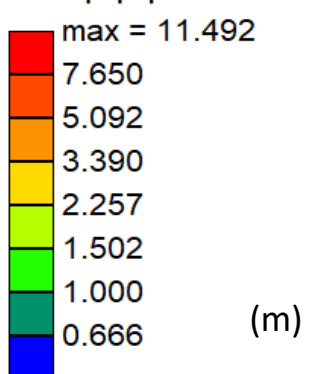

(m)
[001]

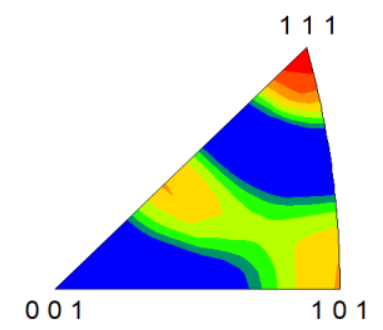

[010]

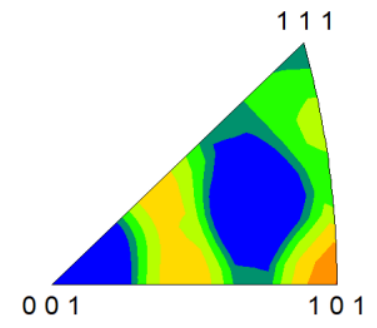

101

[100]
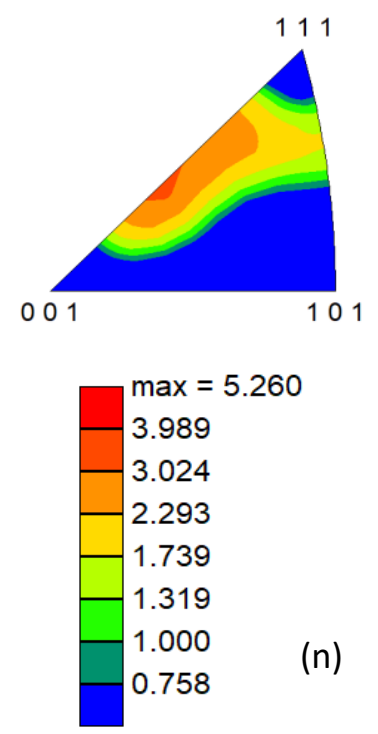

(n)
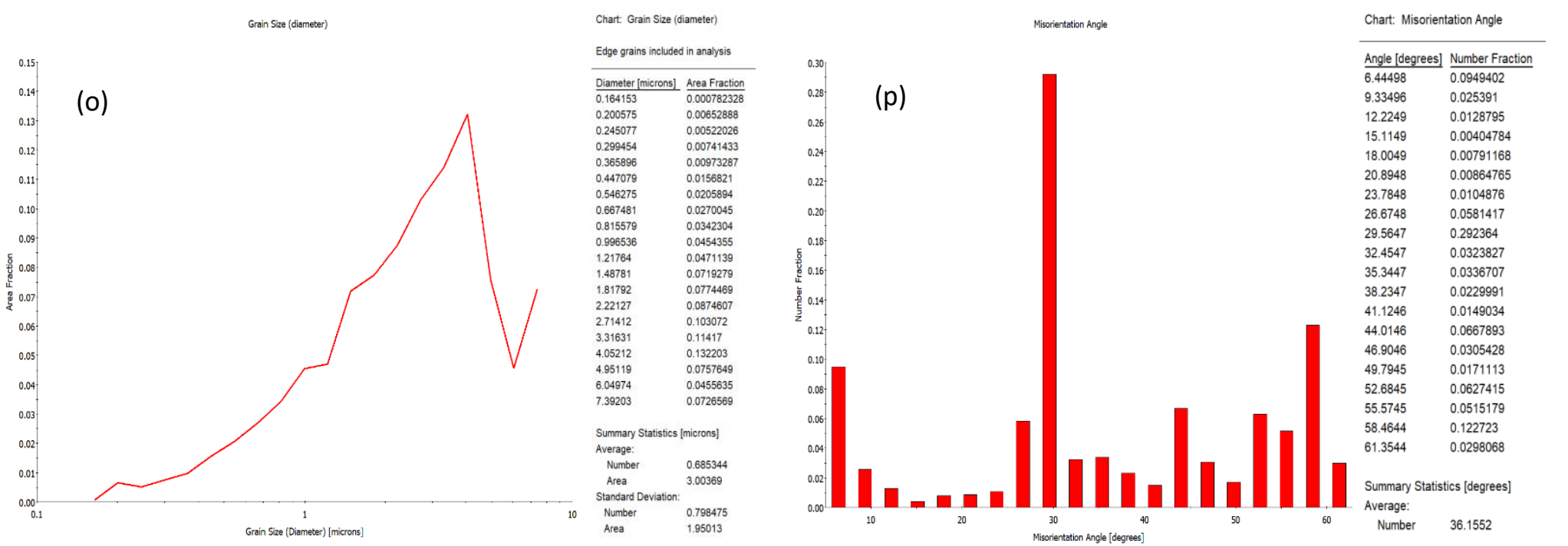
Figure 2 (a) - (p): (a) - (d) Elemental maps of Copper, Zirconium, Aluminium and Oxygen, (e) Image quality of map of $\mathrm{Zr}_{47.5} \mathrm{Cu}_{45.5} \mathrm{Al}_{5} \mathrm{Co}_{2}(0.25 \% \mathrm{ZrC})$ (f) Colour coded orientation map of $\mathrm{Zr}_{47.5} \mathrm{Cu}_{45.5} \mathrm{Al}_{5} \mathrm{Co}_{2}\left(0.25 \% \mathrm{ZrC}\right.$ ) (g) Colour coded orientation map of $\mathrm{Al}_{2} \mathrm{Zr}$ FCC phase [71], (h) and (i) Pole figures of $\mathrm{Al}_{2} \mathrm{Zr}$ FCC phase, (j) - (k) grain size histograms of $\mathrm{Al}_{2} \mathrm{Zr}$ FCC phase, (l) Colour coded orientation map of BCC phase [71], (m) and (n) Pole figures of BCC phase, (o) (p) grain size histograms of BCC phase.

\section{$2.3 \mathrm{ZrC}=0.50 \%$}

As the percentage of inoculant increase from 0.25 to $0.5 \%$, microstructure evolved and as observed via EBSD mapping is shown in figure 3 (a) - (p). As can be easily seen that with increase of percentage of inoculant, length of fcc dendrites increase while their width decrease. They tend to form more of needle like or acicular type structure. This is clear indication of profound effect of inoculation towards promoting crystallinity. They are more closely spaced and have evolved to have more compact morphology. This may have been the reason for increased toughness at this inoculant percentage. Colour coded EDS maps clearly show the evolution of $\mathrm{Cu}, \mathrm{Zr}, \mathrm{Al}$ and oxygen. However, this time any presence of unmelted inoculant is not detected. This may be due to the reason that higher temperatures maintained during this casting [22] promote proper dissolution. As was the case previously, colour coded orientation map can be split for two individual phases. That is face centred cubic (fcc) (Figure $3(\mathrm{~g})$ ) and body centred cubic (bcc) (Figure 3 (1)). Difference of colour once gain indicates presence of grains having different orientations with respect to plane of observation. Size of fcc dendrites can be further divided into three types. Small, medium and large. Size of small dendrites range from average $2 \mu \mathrm{m}$ wide to average $6 \mu \mathrm{m}$ long. Medium dendrites maintain same width while their length increase to $24-26$ $\mu \mathrm{m}$. Lastly, only one large dendrite is observed in the lower middle portion of figure $3(\mathrm{~g})$. This is prominent indication of proper and complete diffusion. Its width has increased to $4 \mu \mathrm{m}$ while its length ranges from $130-140 \mu \mathrm{m}$. Emergence of further small secondary dendrites can also be witnessed from its main trunk specially from thick region where profound diffusion has occurred. It also indicates that there is optimal size (around $4 \mu \mathrm{m}$ ) at which this dendrite tends to stabilize and beyond which it tends to protrude into small branches forming secondary dendrite arms. Further close observation reveals that both very small and one large dendrite are oriented along same direction while medium ones (having blue colour) have different orientation. There is another small fat and short dendrite found in the lower left region of micrograph. It indicates initial stage of development of long dendrite but due to suppressed kinetics, it remained unsuccessful in growing into full dendrite. Grain size histogram (figure $3(\mathrm{k})$ ) shows average grain size to be $0.5635 \mu \mathrm{m}$. Similarly, a careful analysis of colour coded orientation map of body centred cubic phase show mostly small grains spread all throughout the matrix as three-dimensional network. Their spreading indicates jelly type honeycomb structure. Mostly their size is around $1 \mu \mathrm{m}$ wide to $3.2 \mu \mathrm{m}$ long. However, they tend to maintain a lower aspect ratio. Also, mostly they are oriented along one crystallographic direction. Only one area is observed in the middle left of micrograph which has different colour. Thus, indicates presence of different orientations. Their average grain size is $0.8305 \mu \mathrm{m}$. 

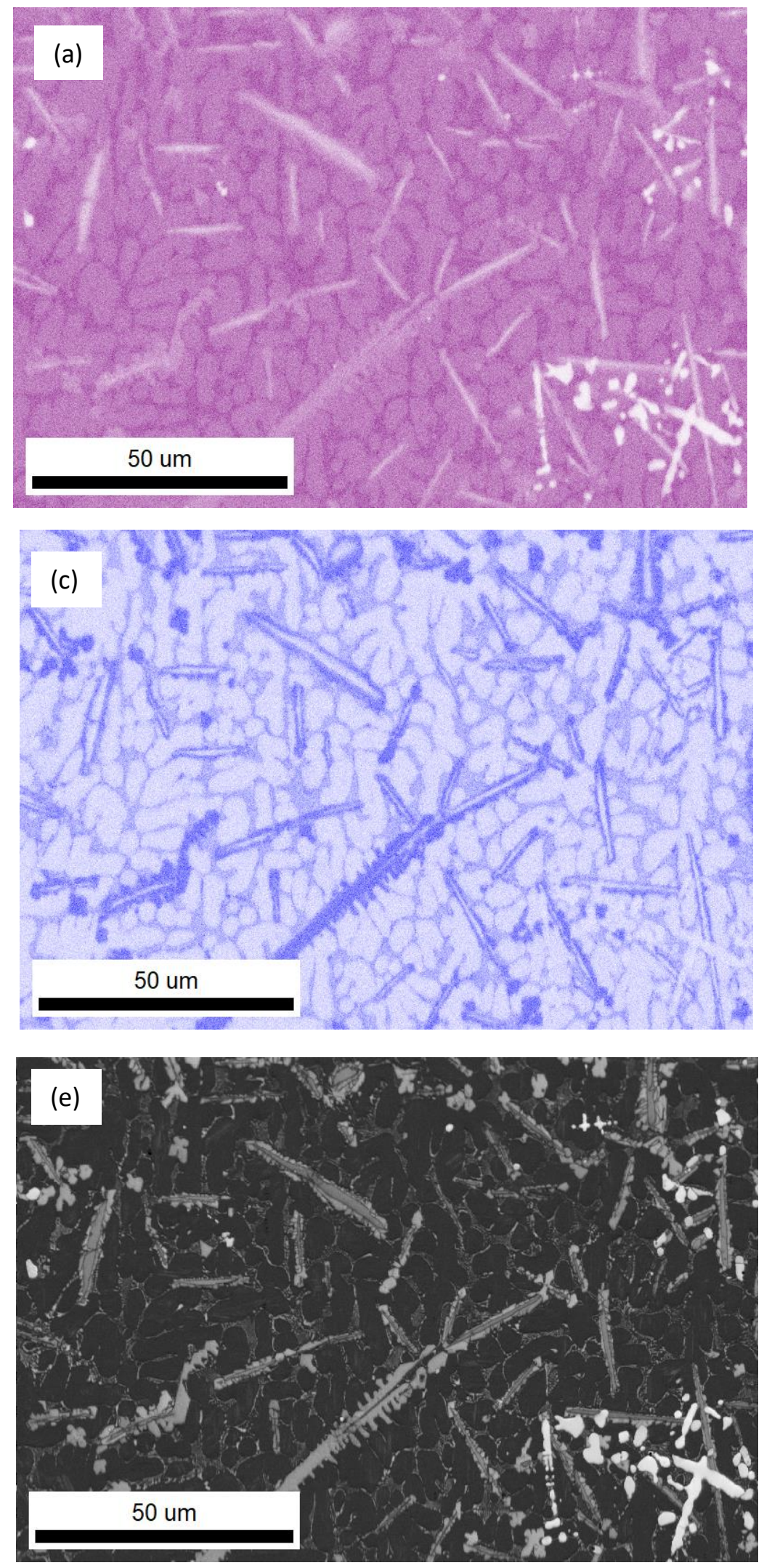

(b)

50 um

(d)

\section{0 um}

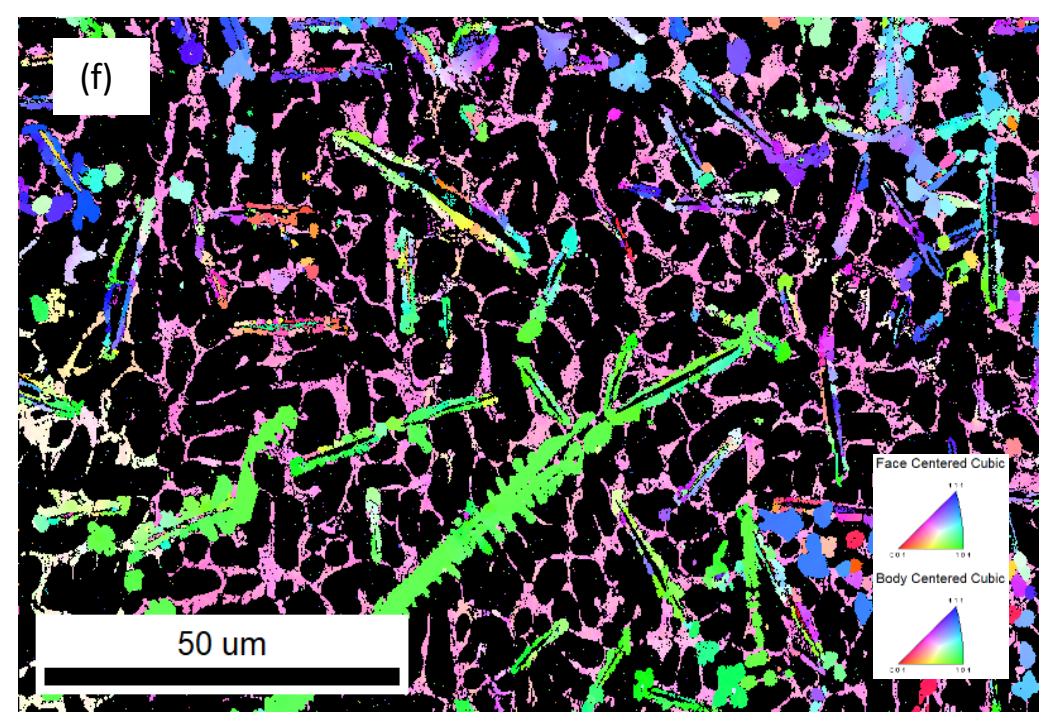



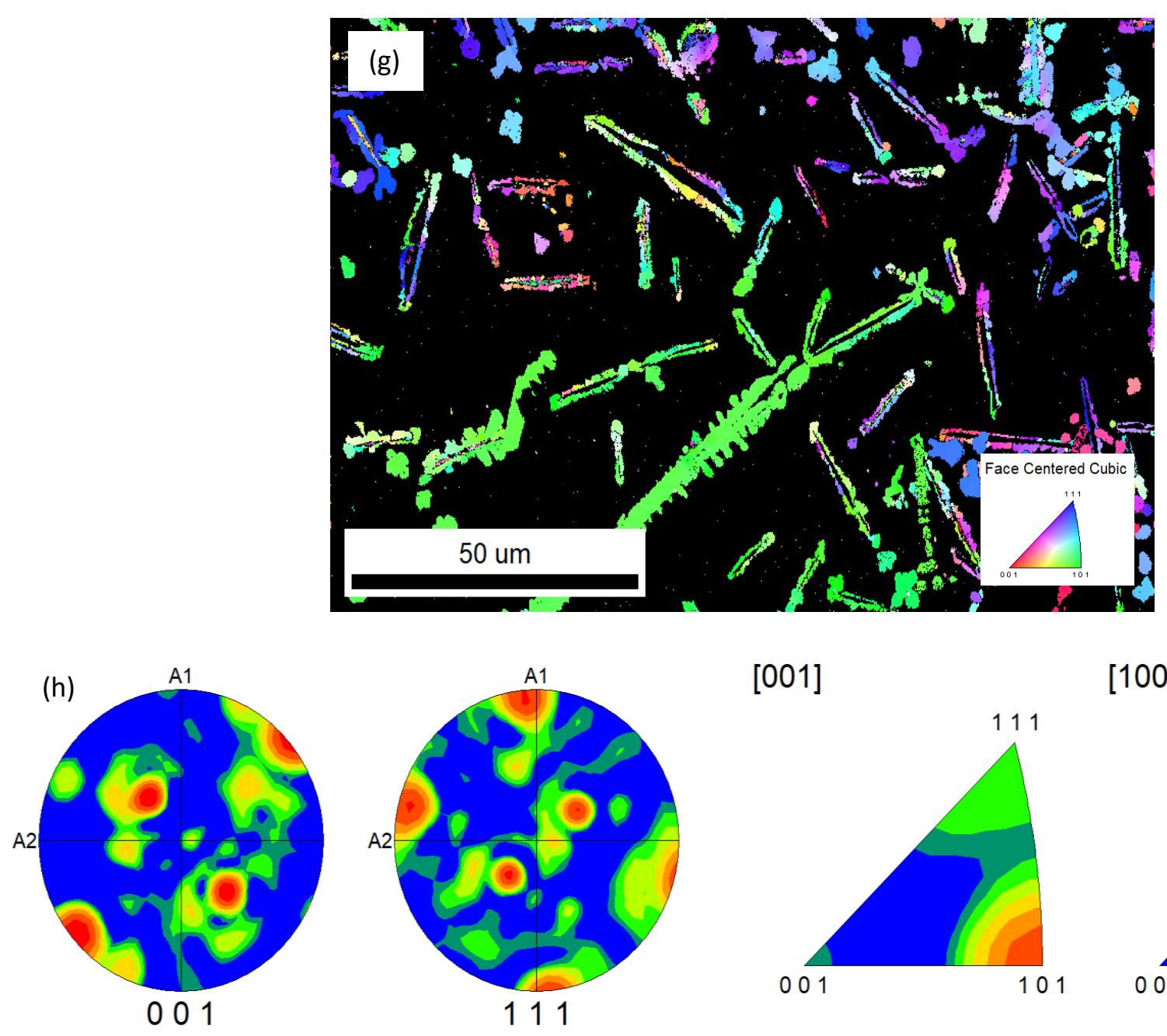

[100]

(i)
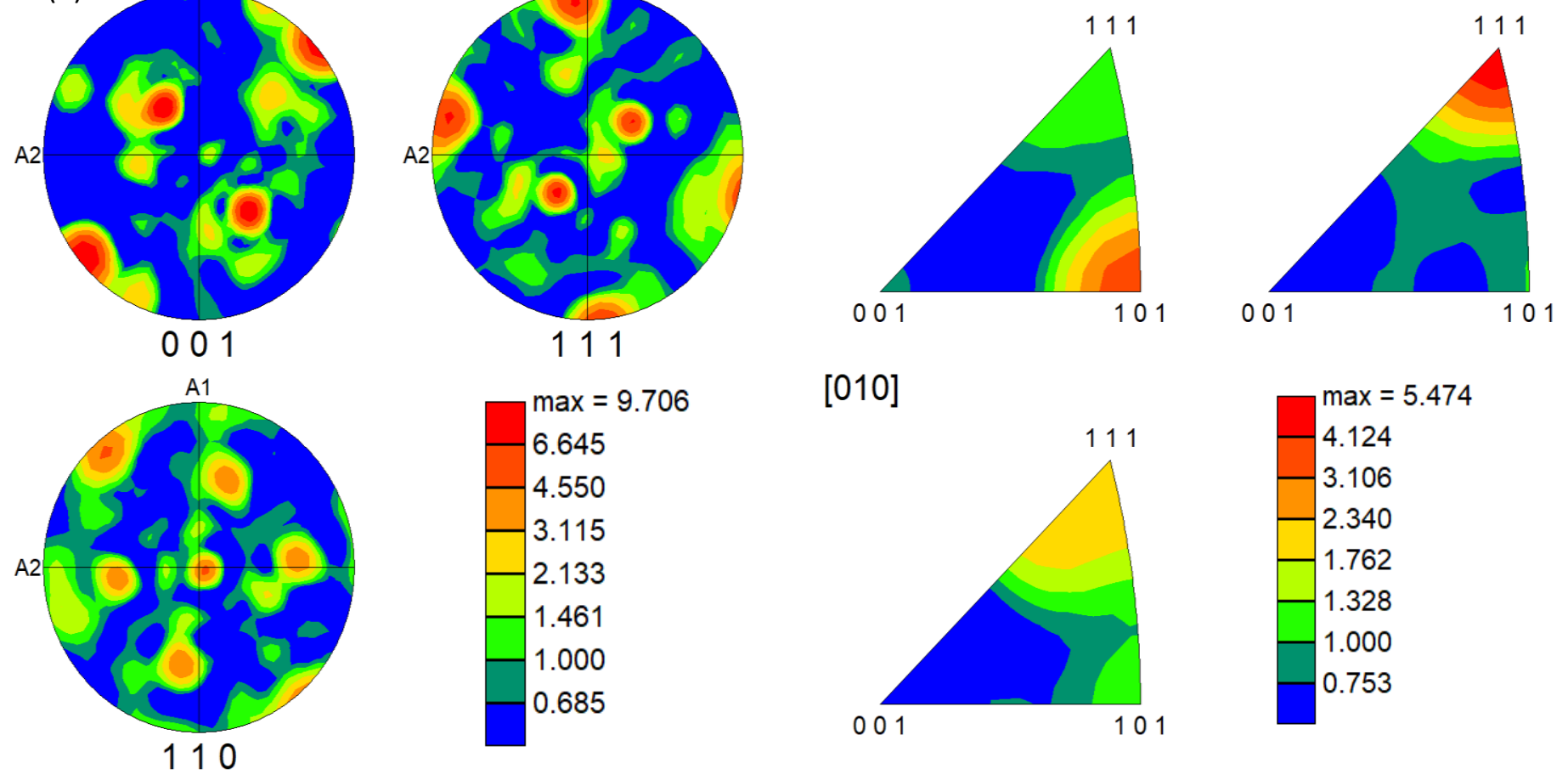

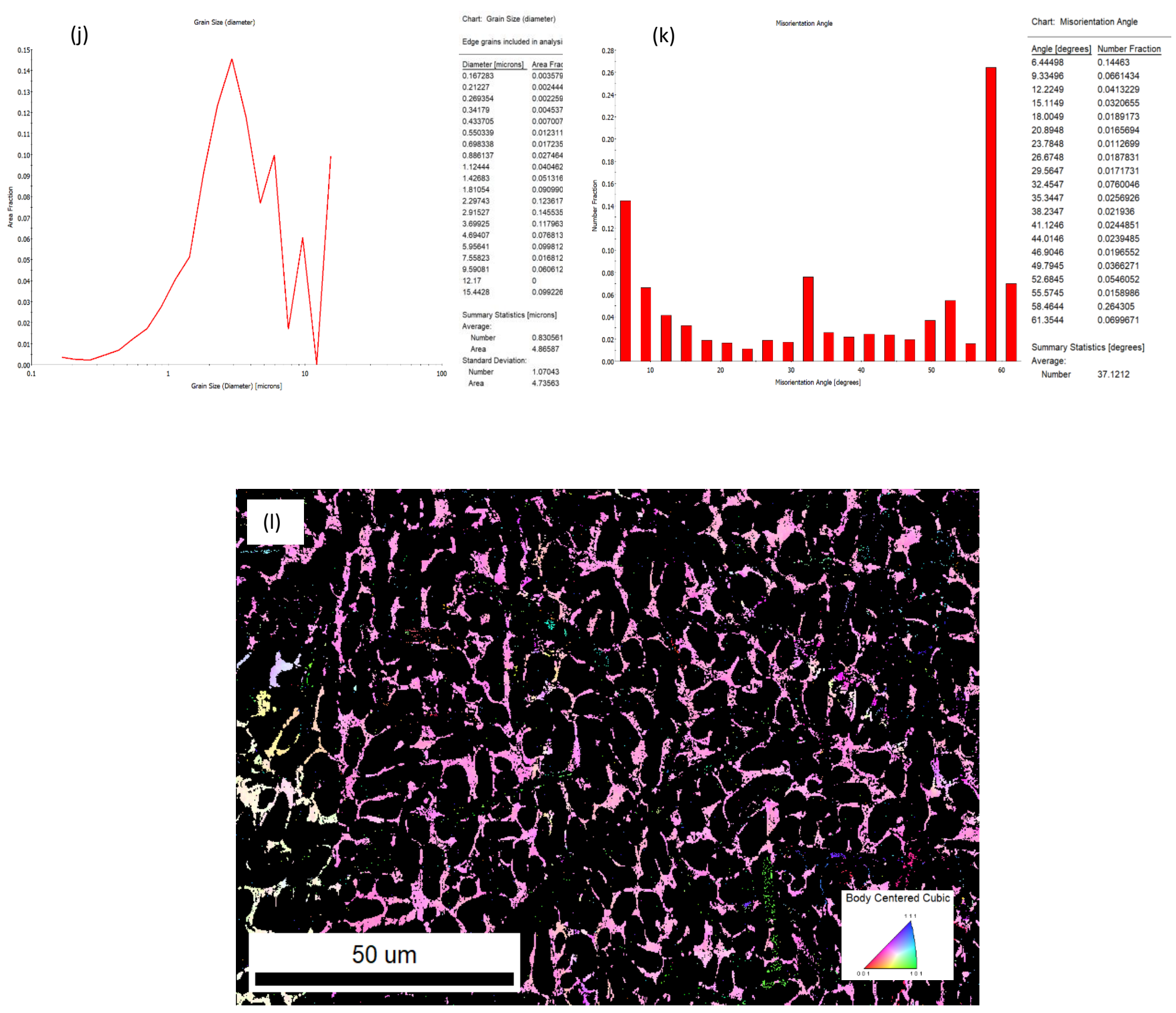


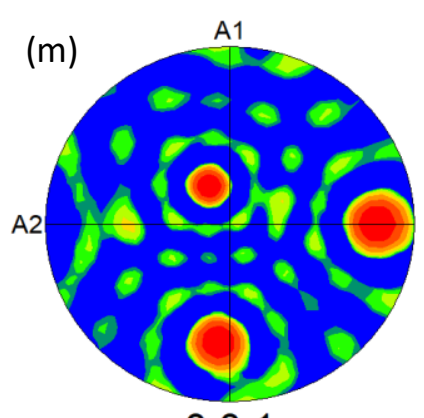

001

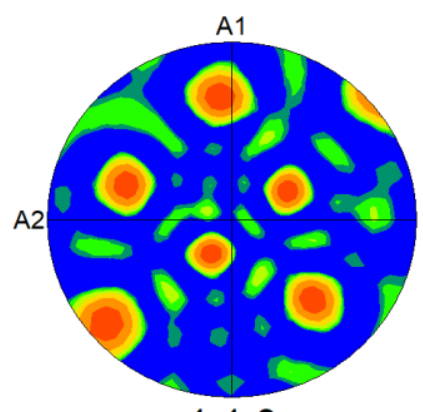

110

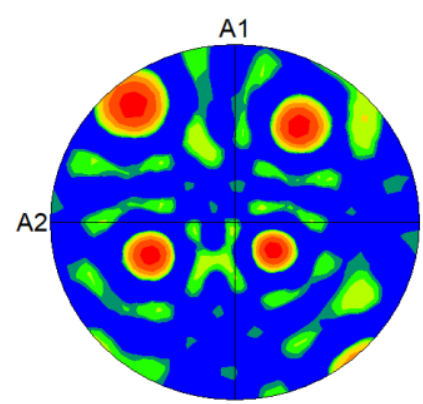

111

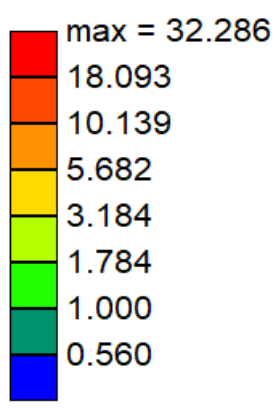

[001]

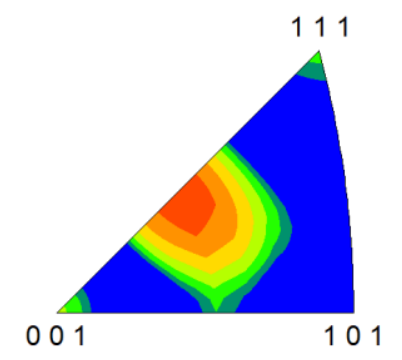

[010]

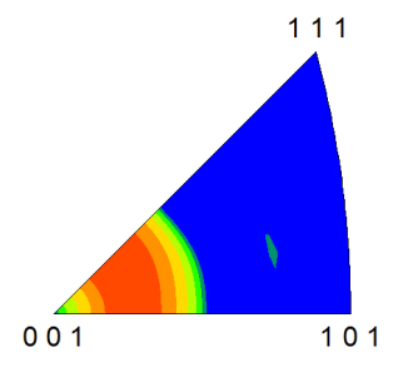

[100]
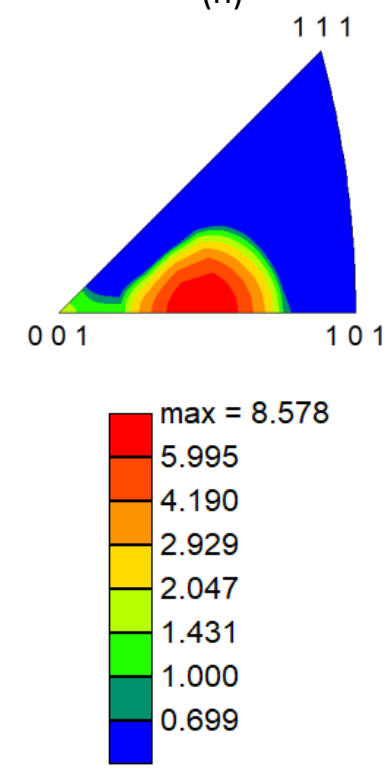

(o)

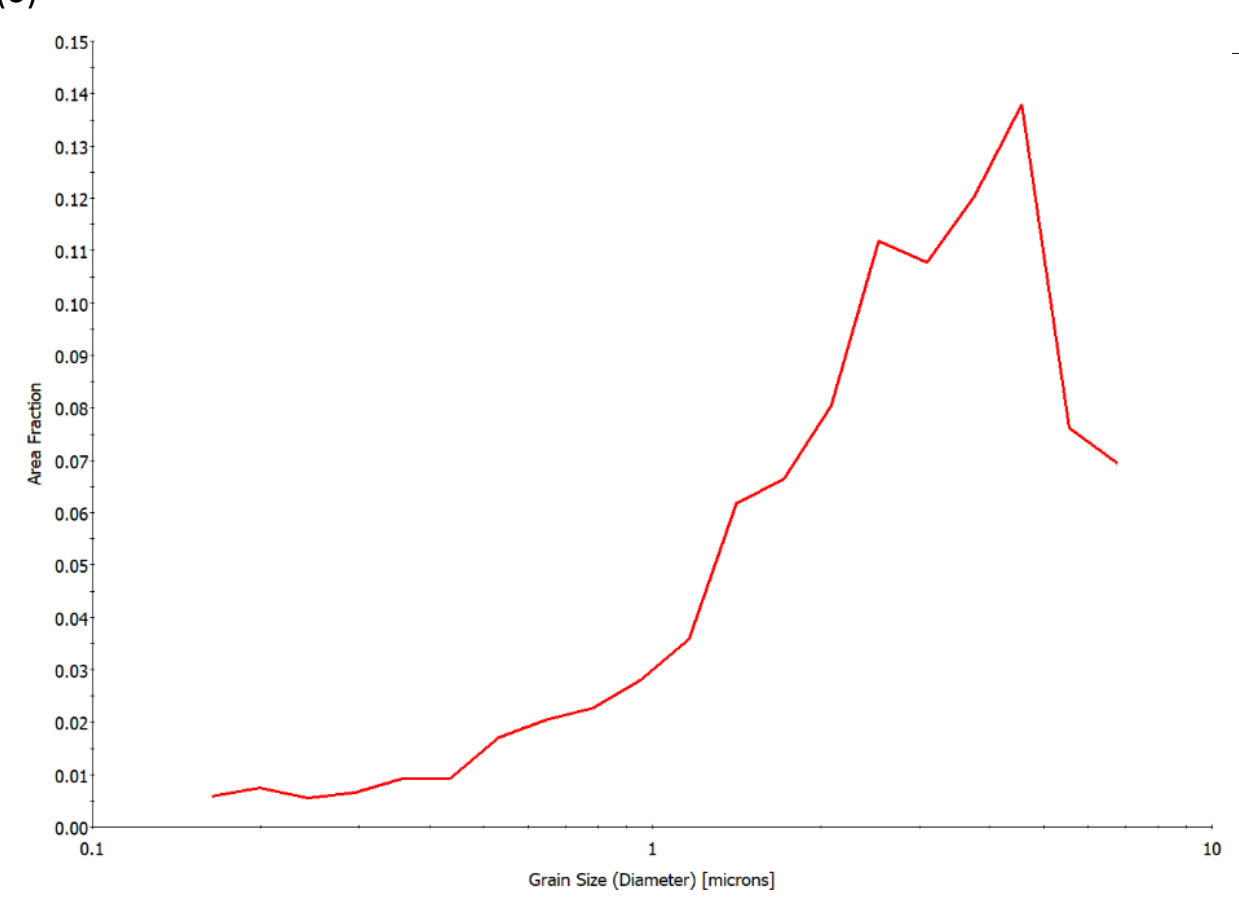

Chart: Grain Size (diameter)

Edge grains included in analysis

Diameter [microns] Area Fraction

$0.163779 \quad \frac{00591942}{0.0074763}$

$0.199208 \quad 0.0074763$

$0.242301 \quad 0.00556668$

$0.294716 \quad 0.00663299$

$0.358469 \quad 0.00920347$

$0.436013 \quad 0.00915077$

$0.530331 \quad 0.0169636$

$0.645052 \quad 0.0204585$

$0.78459 \quad 0.0226722$

$0.954313 \quad 0.0280767$

$\begin{array}{ll}0.16075 & 0.0358692\end{array}$

$1.41184 \quad 0.0617281$

$1.71725 \quad 0.0663907$

$\begin{array}{ll}2.08873 & 0.0804067\end{array}$

$2.54057 \quad 0.111845$

$3.09014 \quad 0.107673$

$3.7586 \quad 0.120403$

$4.57166 \quad 0.137878$

$5.56061 \quad 0.0761983$

$\begin{array}{ll}6.76348 & 0.0694883\end{array}$

Summary Statistics [microns]

Average:

Number $\quad 0.563533$

Area $\quad 3.10152$

Standard Deviation:

Number $\quad 0.780553$

Area $\quad 1.80189$ 


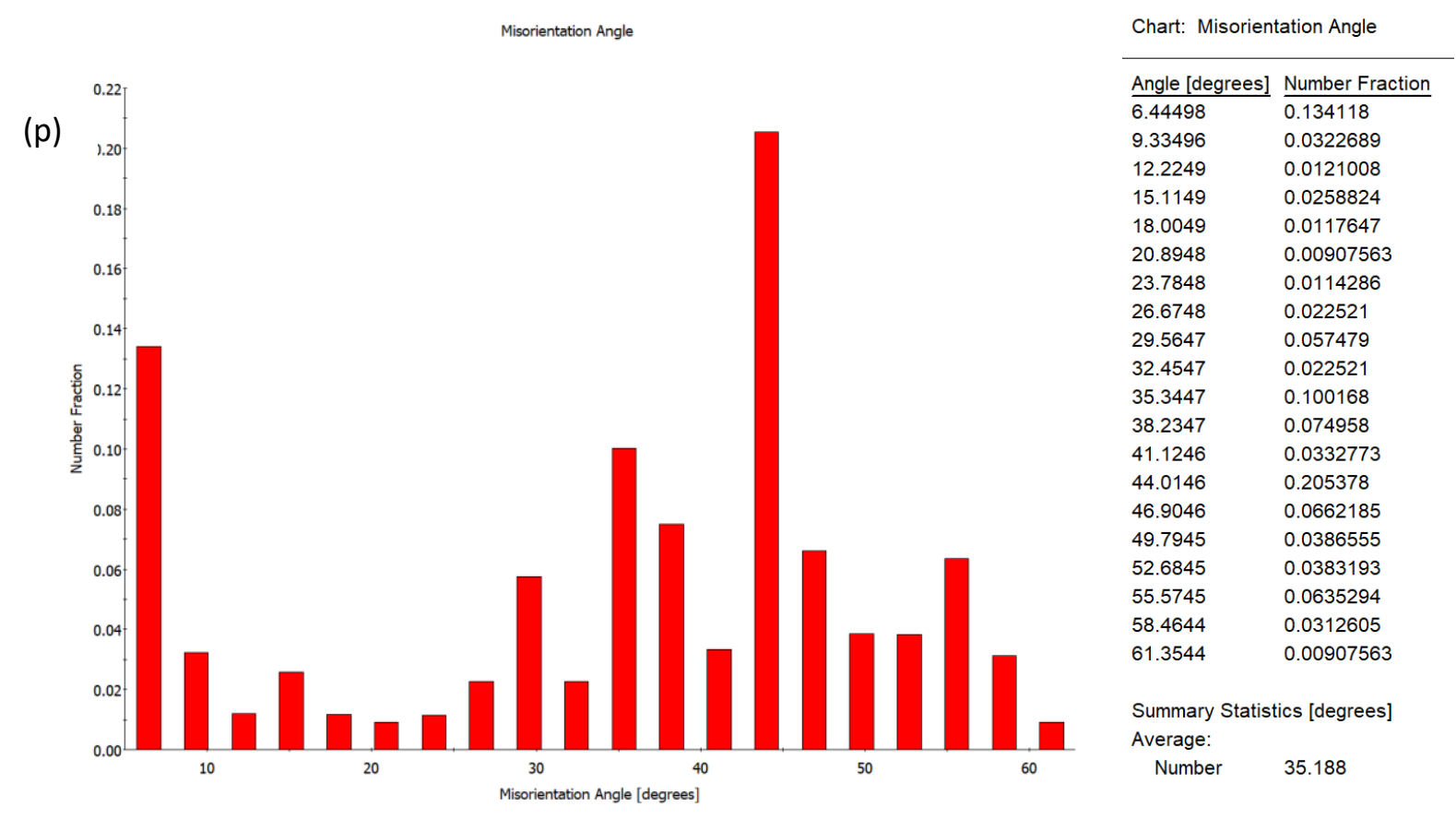

Figure 3 (a) - (p): (a) - (d) Elemental maps of Copper, Zirconium, Aluminium and Oxygen, (e) Image quality of map of $\mathrm{Zr}_{47.5} \mathrm{Cu}_{45.5} \mathrm{Al}_{5} \mathrm{Co}_{2}(0.5 \% \mathrm{ZrC})$ (f) Colour coded orientation map of $\mathrm{Zr}_{47.5} \mathrm{Cu}_{45.5} \mathrm{Al}_{5} \mathrm{Co}_{2}(0.5 \% \mathrm{ZrC})(\mathrm{g})$ Colour coded orientation map of $\mathrm{Al}_{2} \mathrm{Zr}$ FCC phase [71], (h) and (i) Pole figures of $\mathrm{Al}_{2} \mathrm{Zr}$ FCC phase, (j) - (k) Grain size histograms of $\mathrm{Al}_{2} \mathrm{Zr}$ FCC phase, (l) Colour coded orientation map of BCC phase [71], (m) and (n) Pole figures of BCC phase, (o) (p) Grain size histograms of BCC phase.

\section{$2.4 \mathrm{ZrC}=0.75 \%$ and $1.0 \%$}

Alloys with $0.75 \%$ and $1.0 \% \mathrm{ZrC}$ are tested at The University of New South Wales, Sydney, Australia. Unfortunately, improper patterns were captured due to poor workmanship skill which subsequently did not resulted in good Hough Space Transform, indexing and matching with crystal information files. Only color-coded orientation maps are presented (Figure 4 and 5) to give an image of outcome. Most of the data consisted of background noise without detecting any crystallinity. One of the reasons attributed to this is the absence of simultaneous EDS mapping prior EBSD mapping. That is, not enough data points from EDS were available to provide a feedstock for EBSD. Thus, no useful information could be extracted from these maps. These results proved out to be erroneous. An attempt is underway to repeat the same at EDAX Laboratories, Utah and will be presented in subsequent reports. 

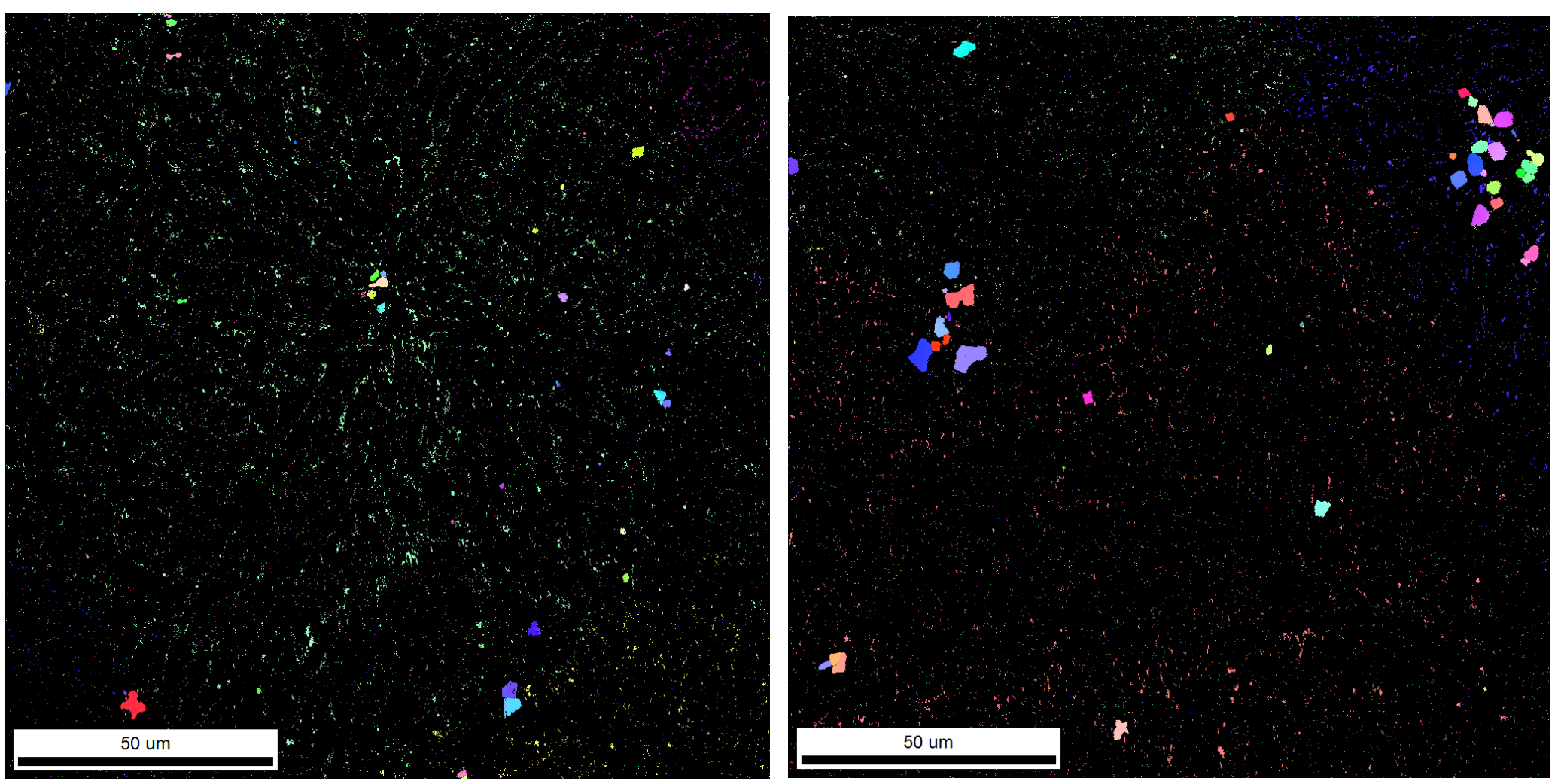

Figure 4 (left) and 5 (right): (Left) Colour coded EBSD map of $\mathrm{Zr}_{47.5} \mathrm{Cu}_{45.5} \mathrm{Al}_{5} \mathrm{Co}_{2}(0.75 \% \mathrm{ZrC})$, (right) Colour coded EBSD map of $\mathrm{Zr}_{47.5} \mathrm{Cu}_{45.5} \mathrm{Al}_{5} \mathrm{Co}_{2}(1.0 \% \mathrm{ZrC})$,

\subsection{Acknowledgements}

Author would like to thank the support, encouragement, patience and perseverance of his supervisors (specially Prof. Milan Brandt and Mrs. Lina Bubic). He would also like to thank Mr. Ron Witt of EBSD Analytical Inc. for help in carrying out quick EBSD scans.

\subsection{Conclusions}

Following conclusions could be drawn from this study;

1. Electron back scatter diffraction shows the effect of inoculation in promoting crystallinity.

2. Eight types of phases may be observed in this family of composites.

3. Unmelted $\mathrm{ZrC}$ is observed at the center of nucleating grain in element maps of $\mathrm{Cu}, \mathrm{Zr}, \mathrm{Al}$ and Oxygen indicating incomplete mixing and heterogeneous nucleation at $\mathrm{ZrC}=0.25 \%$.

4. Size and morphology of fcc dendrites at $\mathrm{ZrC}=0.25 \%$ indicates improper to proper diffusion. On average their size is around $4 \mu \mathrm{m}$ wide to $120 \mu \mathrm{m}$ long (long dendrites).

5. At $\mathrm{ZrC}=0.25 \%$, there is definite orientation relationship between fcc grains in one micrograph and bcc in other indicated by difference of color.

6. Three types of fcc grains namely large, medium and small with needle like or acicular morphology are observed at $\mathrm{ZrC}=0.5 \%$ with an orientation relationship between small 
and large dendrites (same color) and a different relationship for medium size dendrites (different blue color). Their average size is around $0.5635 \mu \mathrm{m}$

7. No unmelted $\mathrm{ZrC}$ is observed at the center of nucleating grain indicating complete melting at high temperature, mixing, homogenization and rapid solidification at $\mathrm{ZrC}=0.5 \%$

8. At inoculant percentage of $0.5 \% \mathrm{ZrC}$, almost all grains of body centered cubic phase are found to lie along one crystallographic plane. Their average grain size is $0.8305 \mu \mathrm{m}$.

\section{References}

1. Greer, A.L., Metallic Glasses. Science, 1995. 267(5206): p. 1947-1953.

2. Güntherodt, H.J., Metallic glasses, in Festkörperprobleme 17: Plenary Lectures of the Divisions "Semiconductor Physics" "Metal Physics" "Low Temperature Physics" "Thermodynamics and Statistical Physics" "Crystallography" "Magnetism" "Surface Physics" of the German Physical Society Münster, March 7-12, 1977, J. Treusch, Editor. 1977, Springer Berlin Heidelberg: Berlin, Heidelberg. p. 25-53.

3. Ashby, M.F. and A.L. Greer, Metallic glasses as structural materials. Scripta Materialia, 2006. 54(3): p. 321-326.

4. Wang, W.H., Metallic glasses: Family traits. Nat Mater, 2012. 11(4): p. 275-276.

5. Klement, W., R.H. Willens, and P.O.L. Duwez, Non-crystalline Structure in Solidified Gold-Silicon Alloys. Nature, 1960. 187(4740): p. 869-870.

6. Choi-Yim, H. and W.L. Johnson, Bulk metallic glass matrix composites. Applied physics letters, 1997. 71(26): p. 3808-3810.

7. Hofmann, D.C., et al., Designing metallic glass matrix composites with high toughness and tensile ductility. Nature, 2008. 451: p. 1085.

8. Abdeljawad, F., M. Fontus, and M. Haataja, Ductility of bulk metallic glass composites: Microstructural effects. Applied Physics Letters, 2011. 98(3): p. 031909.

9. Jiang, J.-Z., et al., Low-Density High-Strength Bulk Metallic Glasses and Their Composites: A Review. Advanced Engineering Materials, 2015. 17(6): p. 761-780.

10. Qiao, J., H. Jia, and P.K. Liaw, Metallic glass matrix composites. Materials Science and Engineering: R: Reports, 2016. 100: p. 1-69.

11. Rafique, M.M.A., Modelling and Simulation of Solidification Phenomena during Additive Manufacturing of Bulk Metallic Glass Matrix Composites (BMGMC)i ${ }^{a} A$ Brief Review and Introduction of Technique. Journal of Encapsulation and Adsorption Sciences, 2018. Vol.08No.02: p. 50.

12. Zhai, H., H. Wang, and F. Liu, A strategy for designing bulk metallic glass composites with excellent work-hardening and large tensile ductility. Journal of Alloys and Compounds, 2016. 685: p. 322-330.

13. Shi, Y. and M.L. Falk, Does metallic glass have a backbone? The role of percolating short range order in strength and failure. Scripta Materialia, 2006. 54(3): p. 381-386.

14. Zhang, Q., et al., Formation of High Strength $\langle 1>$ In-situ</l> Bulk Metallic Glass Composite with Enhanced Plasticity in $C U<S U B>50</ S U B>Z r<S U B>47.5</ S U B>T i<S U B>2.5</ S U B>A l l o y$. MATERIALS TRANSACTIONS, 2005. 46(3): p. 730-733.

15. Inoue, A., High Strength Bulk Amorphous Alloys with Low Critical Cooling Rates (<l>Overview</I>). Materials Transactions, JIM, 1995. 36(7): p. 866-875.

16. Chen, M., Mechanical Behavior of Metallic Glasses: Microscopic Understanding of Strength and Ductility. Annual Review of Materials Research, 2008. 38(1): p. 445-469. 
17. Si, J.J., et al., Cr-based bulk metallic glasses with ultrahigh hardness. Applied Physics Letters, 2015. 106(25): p. 251905.

18. Ramamurty, U., et al., Hardness and plastic deformation in a bulk metallic glass. Acta Materialia, 2005. 53(3): p. 705-717.

19. Keryvin, V., V.H. Hoang, and J. Shen, Hardness, toughness, brittleness and cracking systems in an iron-based bulk metallic glass by indentation. Intermetallics, 2009. 17(4): p. 211-217.

20. Narayan, R.L., et al., On the hardness and elastic modulus of bulk metallic glass matrix composites. Scripta Materialia, 2010. 63(7): p. 768-771.

21. Pan, X.F., et al., Vickers hardness and compressive properties of bulk metallic glasses and nanostructure-dendrite composites. Journal of Materials Research, 2005. 20(10): p. 2632-2638.

22. Rafique, M.M.A., Production and Characterization of Zr Based Bulk Metallic Glass Matrix Composites (BMGMC) in the Form of Wedge Shape Ingots. Engineering, 2018. Vol.10No.04: p. 31.

23. Inoue, A., et al., Production methods and properties of engineering glassy alloys and composites. Intermetallics, 2015. 58: p. 20-30.

24. Gludovatz, B., et al., On the understanding of the effects of sample size on the variability in fracture toughness of bulk metallic glasses. Acta Materialia, 2017. 126: p. 494-506.

25. Zameer Abbas, S., F. Ahmad Khalid, and H. Zaigham, Indentation fracture toughness behavior of FeCo-based bulk metallic glass intrinsic composites. Journal of Non-Crystalline Solids, 2017. 457: p. 86-92.

26. Chen, L.Y., et al., New Class of Plastic Bulk Metallic Glass. Physical Review Letters, 2008. 100(7): p. 075501.

27. Lee, H., et al., Hypervelocity Impact Phenomenon in Bulk Metallic Glasses and Composites**. Advanced Engineering Materials, 2014. 16(1): p. 85-93.

28. Fecht, H.-J. and R.K. Wunderlich, Fundamentals of Liquid Processing in Low Earth Orbit: From Thermophysical Properties to Microstructure Formation in Metallic Alloys. JOM, 2017. 69(8): p. 1261-1268.

29. C., H.D., et al., Hypervelocity Impact Testing of a Metallic Glass-Stuffed Whipple Shield. Advanced Engineering Materials, 2015. 17(9): p. 1313-1322.

30. Choi, H., et al., Tribological behavior of the kinetic sprayed Ni59Ti16Zr20Si2Sn3 bulk metallic glass. Journal of Alloys and Compounds, 2007. 434-435: p. 64-67.

31. Hofmann, D.C., Shape Memory Bulk Metallic Glass Composites. Science, 2010. 329(5997): p. 1294-1295.

32. Gargarella, P., et al., Ti-Cu-Ni shape memory bulk metallic glass composites. Acta Materialia, 2013. 61(1): p. 151-162.

33. Hofmann, D.C., et al., Castable Bulk Metallic Glass Strain Wave Gears: Towards Decreasing the Cost of High-Performance Robotics. Scientific Reports, 2016. 6: p. 37773.

34. C., H.D., et al., Optimizing Bulk Metallic Glasses for Robust, Highly Wear-Resistant Gears Advanced Engineering Materials, 2017. 19(1): p. 1600541.

35. Li, H., et al., Compressive Behavior of a Zr-Based Metallic Glass at Cryogenic Temperatures. Advanced Materials, 2006. 18(6): p. 752-754.

36. Zhu, Z., et al., Ta-particulate reinforced Zr-based bulk metallic glass matrix composite with tensile plasticity. Scripta Materialia, 2010. 62(5): p. 278-281.

37. Fan, C., et al., Mechanical Behavior of Bulk Amorphous Alloys Reinforced by Ductile Particles at Cryogenic Temperatures. Physical Review Letters, 2006. 96(14): p. 145506.

38. Choi-Yim, H., et al., Processing, microstructure and properties of ductile metal particulate reinforced Zr57Nb5Al10Cu15.4Ni12.6 bulk metallic glass composites. Acta Materialia, 2002. 50(10): p. 2737-2745. 
39. Liu, J., et al., In situ spherical B2 CuZr phase reinforced ZrCuNiAlNb bulk metallic glass matrix composite. Journal of Materials Research, 2010. 25(6): p. 1159-1163.

40. Fan, C., R.T. Ott, and T.C. Hufnagel, Metallic glass matrix composite with precipitated ductile reinforcement. Applied Physics Letters, 2002. 81(6): p. 1020-1022.

41. Jiang, F., et al., Microstructure evolution and mechanical properties of Cu46Zr47Al7 bulk metallic glass composite containing CuZr crystallizing phases. Materials Science and Engineering: A, 2007. 467(1-2): p. 139-145.

42. Chen, G., et al., Enhanced plasticity in a Zr-based bulk metallic glass composite with in situ formed intermetallic phases. Applied Physics Letters, 2009. 95(8): p. 081908.

43. Guo, W. and H. Kato, Development and microstructure optimization of Mg-based metallic glass matrix composites with in situ B2-NiTi dispersoids. Materials \& Design, 2015. 83: p. 238-248.

44. Jeon, C., et al., Effects of Effective Dendrite Size on Tensile Deformation Behavior in Ti-Based Dendrite-Containing Amorphous Matrix Composites Modified from Ti-6Al-4V Alloy. Metallurgical and Materials Transactions A, 2015. 46(1): p. 235-250.

45. Zhang, T., et al., Dendrite size dependence of tensile plasticity of in situ Ti-based metallic glass matrix composites. Journal of Alloys and Compounds, 2014. 583: p. 593-597.

46. Kim, D.H., et al., Phase separation in metallic glasses. Progress in Materials Science, 2013. 58(8): p. 1103-1172.

47. Basu, J., et al., Microstructure and mechanical properties of a partially crystallized La-based bulk metallic glass. Philosophical Magazine, 2003. 83(15): p. 1747-1760.

48. Taub, A.I. and F. Spaepen, The kinetics of structural relaxation of a metallic glass. Acta Metallurgica, 1980. 28(12): p. 1781-1788.

49. Zhang, Y., W.H. Wang, and A.L. Greer, Making metallic glasses plastic by control of residual stress. Nature Materials, 2006. 5: p. 857.

50. Fan, C., et al., Properties of as-cast and structurally relaxed Zr-based bulk metallic glasses. Journal of Non-Crystalline Solids, 2006. 352(2): p. 174-179.

51. Krämer, L., Y. Champion, and R. Pippan, From powders to bulk metallic glass composites. Scientific Reports, 2017. 7(1): p. 6651.

52. Brothers, A.H. and D.C. Dunand, Ductile Bulk Metallic Glass Foams. Advanced Materials, 2005. 17(4): p. 484-486.

53. Liu, Z., et al., Pronounced ductility in CuZrAl ternary bulk metallic glass composites with optimized microstructure through melt adjustment. AIP Advances, 2012. 2(3): p. 032176.

54. Cheng, J.-L., et al., Innovative approach to the design of low-cost Zr-based BMG composites with good glass formation. Scientific Reports, 2013. 3: p. 2097.

55. Harooni, A., et al., Processing window development for laser cladding of zirconium on zirconium alloy. Journal of Materials Processing Technology, 2016. 230: p. 263-271.

56. Hays, C.C., C.P. Kim, and W.L. Johnson, Microstructure Controlled Shear Band Pattern Formation and Enhanced Plasticity of Bulk Metallic Glasses Containing Itextit\{in situ\} Formed Ductile Phase Dendrite Dispersions. Physical Review Letters, 2000. 84(13): p. 2901-2904.

57. Scudino, S., et al., Ductile bulk metallic glasses produced through designed heterogeneities. Scripta Materialia, 2011. 65(9): p. 815-818.

58. Gargarella, P., et al., Phase formation and mechanical properties of Ti-Cu-Ni-Zr bulk metallic glass composites. Acta Materialia, 2014. 65: p. 259-269.

59. Das, J., et al., "Work-Hardenable" Ductile Bulk Metallic Glass. Physical Review Letters, 2005. 94(20): p. 205501.

60. Das, J., et al., Plasticity in bulk metallic glasses investigated via the strain distribution. Physical Review B, 2007. 76(9): p. 092203. 
61. Kim, K.B., et al., Heterogeneous distribution of shear strains in deformed Ti66.1Cu8Ni4.8Sn7.2Nb13.9 nanostructure-dendrite composite. physica status solidi (a), 2005. 202(13): p. 2405-2412.

62. Fan, C., C. Li, and A. Inoue, Nanocrystal composites in $\mathrm{Zr}-\mathrm{Nb}-\mathrm{Cu}-\mathrm{Al}$ metallic glasses. Journal of Non-Crystalline Solids, 2000. 270(1-3): p. 28-33.

63. Hofmann, D.C., et al., Development of tough, low-density titanium-based bulk metallic glass matrix composites with tensile ductility. Proceedings of the National Academy of Sciences, 2008. 105(51): p. 20136-20140.

64. Zhang, L., et al., Distribution of Be in a Ti-Based Bulk Metallic Glass Composite Containing B-Ti. Journal of Materials Science \& Technology, 2017. 33(7): p. 708-711.

65. Booth, J., J. Lewandowski, and J. Carter, EBSD Analysis for Microstructure Characterization of Zrbased Bulk Metallic Glass Composites. Microscopy and Microanalysis, 2014. 20(S3): p. 852-853.

66. Hofmann, D.C. and W.L. Johnson. Improving Ductility in Nanostructured Materials and Metallic Glasses: "Three Laws". in Materials Science Forum. 2010. Trans Tech Publ.

67. Sun, H. and K.M. Flores, Microstructural Analysis of a Laser-Processed Zr-Based Bulk Metallic Glass. Metallurgical and Materials Transactions A, 2010. 41(7): p. 1752-1757.

68. Park, E.S. and D.H. Kim, Design of Bulk metallic glasses with high glass forming ability and enhancement of plasticity in metallic glass matrix composites: A review. Metals and Materials International, 2005. 11(1): p. 19-27.

69. Inoue, A., T. Zhang, and E. Makabe, Production methods of metallic glasses by a suction casting method. 1998, Google Patents.

70. Inoue, A. and A. Takeuchi, Recent development and application products of bulk glassy alloys. Acta Materialia, 2011. 59(6): p. 2243-2267.

71. Jiang, S.-S., et al., A CuZr-based bulk metallic glass composite with excellent mechanical properties by optimizing microstructure. Journal of Non-Crystalline Solids, 2018. 483: p. 94-98.

72. Liu, Z., et al., Microstructural tailoring and improvement of mechanical properties in CuZr-based bulk metallic glass composites. Acta Materialia, 2012. 60(6): p. 3128-3139.

73. Rafique, M.M.A., D. Qiu, and M. Easton, Modeling and simulation of microstructural evolution in Zr based Bulk Metallic Glass Matrix Composites during solidification. MRS Advances. 2(58-59): p. 3591-3606.

74. Pekarskaya, E., C.P. Kim, and W.L. Johnson, In situ transmission electron microscopy studies of shear bands in a bulk metallic glass based composite. Journal of Materials Research, 2001. 16(09): p. 2513-2518.

75. Zu, F.-Q., Temperature-Induced Liquid-Liquid Transition in Metallic Melts: A Brief Review on the New Physical Phenomenon. Metals, 2015. 5(1): p. 395.

76. Guo, G.-Q., et al., Detecting Structural Features in Metallic Glass via Synchrotron Radiation Experiments Combined with Simulations. Metals, 2015. 5(4): p. 2093.

77. Guo, G.-Q., et al., How Can Synchrotron Radiation Techniques Be Applied for Detecting Microstructures in Amorphous Alloys? Metals, 2015. 5(4): p. 2048.

78. Michalik, S., et al., Structural modifications of swift-ion-bombarded metallic glasses studied by high-energy X-ray synchrotron radiation. Acta Materialia, 2014. 80: p. 309-316.

79. Bai, J., et al., Temperature dependent dynamic flow behavior of an in-situ Ti-based bulk metallic glass composite. Materials Science and Engineering: A, 2015. 627: p. 21-26.

80. Qiao, J.W., et al., A Tensile Deformation Model for In-situ Dendrite/Metallic Glass Matrix Composites. Scientific Reports, 2013. 3: p. 2816.

81. El-Dasher, B. and A. Deal, Application of electron backscatter diffraction to phase identification, in Electron backscatter diffraction in materials science. 2009, Springer. p. 81-95. 
82. Schwarzer, R.A., Automated electron backscatter diffraction: present state and prospects, in Electron Backscatter Diffraction in Materials Science. 2000, Springer. p. 105-122.

83. Michael, J., Electron Backscatter Diffraction in the SEM: A Tutorial. Microscopy and Microanalysis, 2002. 8(S02): p. 724-725.

84. Schwarzer, R.A., et al., Present state of electron backscatter diffraction and prospective developments, in Electron backscatter diffraction in materials science. 2009, Springer. p. 1-20.

85. Field, D., Improving the spatial resolution of EBSD. Microscopy and Microanalysis, 2005. 11(S02): p. 52-53.

86. Avishai, A., et al., Transmission EBSD-Bridging the Gap between SEM and TEM. Microscopy and Microanalysis, 2013. 19(S2): p. 694-695.

87. Britton, T.B., et al., Tutorial: Crystal orientations and EBSD - Or which way is up? Materials Characterization, 2016. 117: p. 113-126.

88. Wright, S.I., et al., Electron imaging with an EBSD detector. Ultramicroscopy, 2015. 148: p. 132145.

89. Yeh, M.-C., et al., The Microstructure of Zr-Based Bulk Metallic Glass and Glass Matrix Composite.

90. Chen, T.-H. and C.-K. Tsai, The Microstructural Evolution and Mechanical Properties of Zr-Based Metallic Glass under Different Strain Rate Compressions. Materials, 2015. 8(4): p. 1831.

91. Oh, Y.S., et al., Microstructure and tensile properties of high-strength high-ductility Ti-based amorphous matrix composites containing ductile dendrites. Acta Materialia, 2011. 59(19): p. 7277-7286.

92. Kim, C.P., et al., Realization of high tensile ductility in a bulk metallic glass composite by the utilization of deformation-induced martensitic transformation. Scripta Materialia, 2011. 65(4): p. 304-307.

93. Guo, Z.-x., et al., Beryllium-distribution in metallic glass matrix composite containing beryllium. Transactions of Nonferrous Metals Society of China, 2017. 27(1): p. 110-116.

94. Borrajo-Pelaez, R. and P. Hedström, Recent Developments of Crystallographic Analysis Methods in the Scanning Electron Microscope for Applications in Metallurgy. Critical Reviews in Solid State and Materials Sciences, 2018. 43(6): p. 455-474.

95. Zhou, W. and Z.L. Wang, Scanning Microscopy for Nanotechnology: Techniques and Applications. 2007: Springer New York.

96. Kikuchi Bands in Low-Energy Electron Diffraction. Journal of Applied Physics, 1966. 37(4): p. 1945-1946.

97. Wilkinson, A.J. and P.B. Hirsch, Electron diffraction based techniques in scanning electron microscopy of bulk materials. Micron, 1997. 28(4): p. 279-308.

98. Aboki, T.A., Development of Fe-B Based Bulk Metallic Glasses: Morphology of Residual Phases in Fe50Ni16Mo6B18Zr10 Glass. Metals, 2013. 3(2): p. 159-177.

99. Wright, S.I., et al., Introduction and comparison of new EBSD post-processing methodologies. Ultramicroscopy, 2015. 159: p. 81-94.

100. Rafique, M.M.A., Effect of Inoculation on Phase Formation and Indentation Hardness Behaviour of Zr\&It;SUB\&gt;47.5\&It;/SUB\&gt;Cu\&It;SUB\&gt;45.5\&It;/SUB\&gt;Al\&It;SUB\&gt;5\&It;/SUB\&gt;Co $\& / t ; S U B \& g t ; 2 \& / t ; / S U B \& g t ;$ and Zr\&lt;SUB\&gt;65\&lt;/SUB\&gt;Cu\&lt;SUB\&gt;15\&lt;/SUB\&gt;Al\&lt;SUB\&gt;10\&lt;/SUB\&gt;Ni\&lt; SUB\&gt;10\&lt;/SUB\&gt; Bulk Metallic Glass Matrix Composites. Engineering, 2018. Vol.10No.08: p. 30.

101. Audebert, F., et al., Production of glassy metallic layers by laser surface treatment. Scripta Materialia, 2003. 48(3): p. 281-286. 
102. Zhang, L., et al., Developing 6-type bulk metallic glass composites from Ti/Zr-based bulk metallic glasses by an iteration method. Journal of Alloys and Compounds, 2018. 740: p. 639-646. 